\title{
Evaluation of Dynamic Materials Procured from Waste Biomass
}

\author{
Ashish Chauhan and Balbir Kaith \\ Dr. B.R. Ambedkar National Institute of Technology, Jalandhar 144 011, India \\ Correspondence should be addressed to Ashish Chauhan, aashishchauhan26@gmail.com
}

Received 6 April 2011; Accepted 14 May 2011

Academic Editor: H. Ku

Copyright () 2011 A. Chauhan and B. Kaith. This is an open access article distributed under the Creative Commons Attribution License, which permits unrestricted use, distribution, and reproduction in any medium, provided the original work is properly cited.

\begin{abstract}
Methyl acrylate (MA) monomer was graft copolymerized onto Hibiscus sabdariffa stem fiber and used to explore the additive effect of vinyl acrylate (VA) and ethyl acrylate (EA) on percentage grafting and the properties of the fiber, in binary vinyl monomeric mixtures. The graft copolymers were reinforced into phenol-formaldehyde polymer matrix to form biocomposites and characterized by FTIR, XRD, TGA, DTA, and SEM techniques. They were evaluated for physico-chemical changes in properties like moisture absorption at different relative humidity levels and chemical resistance against $1 \mathrm{~N} \mathrm{NaOH}$ and $1 \mathrm{~N} \mathrm{HCl}$. These graft copolymers-reinforced biocomposites had higher mechanical strength like hardness, modulus of rupture, modulus of elasticity, and stress at the limit of proportionality. These novel materials can have numerous scientific and industrial applications for the development of technology.
\end{abstract}

\section{Introduction}

Graft copolymerization is a magnificent technique for incorporating the desired properties into raw fiber without drastically affecting its basic traits. It imparts additional features such as thermal and chemical resistance to the naturally existing backbone for their use in various fields. Natural fibers such as ramie, flax, jute, and pine needle are the most suitable reinforcement materials because of their relatively high strength and stiffness for their use in industries such as automobile, packaging, and construction materials that fulfill the economic and ecological requirements.

Composites are the wonder materials, which after meeting the challenges of aerospace have cascaded down for catering the domestic and industrial avenues. Phenoplasts have a wide range of applications as lacquer, varnish, molding compounds, laminate for wall panel, and table top. In the recent times many successful efforts have been made to prepare phenol-formaldehyde composites and to increase its mechanical potential by using different reinforcements like wood particle, hemp scotch, banana fiber, and cellulose fiber [1-6].

Hibiscus sabdariffa (Roselle) is a rich source of cellulose found in abundance throughout the world and has attained prominence as a jute substitute, and attempts are being made to extend its cultivation in areas which are not favorable for jute cultivation. It shows better mechanical properties when studied for injection-molded isotactic polypropylene/Roselle fiber composites $[7,8]$. The versatility of this magnificent chemical technique inspired the thoughts to implement it onto Hibiscus sabdariffa stem fiber by using effective methyl acrylate as principal monomer and explore its cumulative effect in binary vinyl monomer mixture and on the properties of the fiber using ethyl acrylate and vinyl acrylate as secondary monomer and to use the raw fiber, graft copolymers as reinforcement in phenol-formaldehyde polymer matrix-based composite that remains unexplored.

\section{Experimental}

2.1. Materials. H. sabdariffa fiber was obtained from the Department of Agronomy, Chaudhary Sarwan Kumar Himachal Krishi Vishwavidyalaya, Palampur, India. Monomers (Merck), phenol (s. d fine-Chem. Ltd., India), formaldehyde (CDH, India) and ceric ammonium nitrate (S.D. Fine Chem, Pvt. Ltd, Mumbai, India) were used as received. H. sabdariffa fiber was purified through Soxhlet extraction in acetone for 72 hours. 


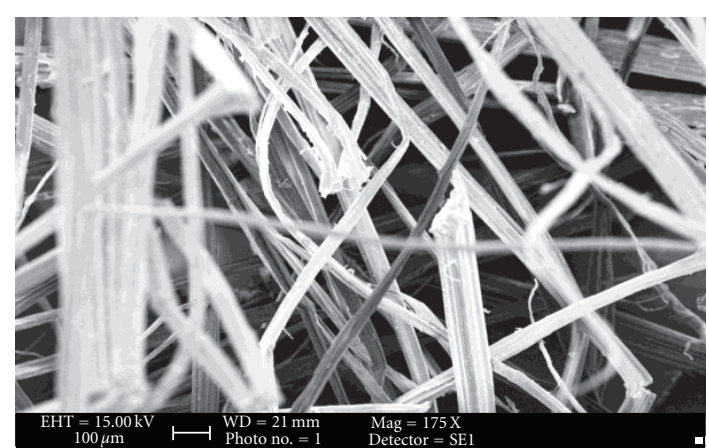

(a)

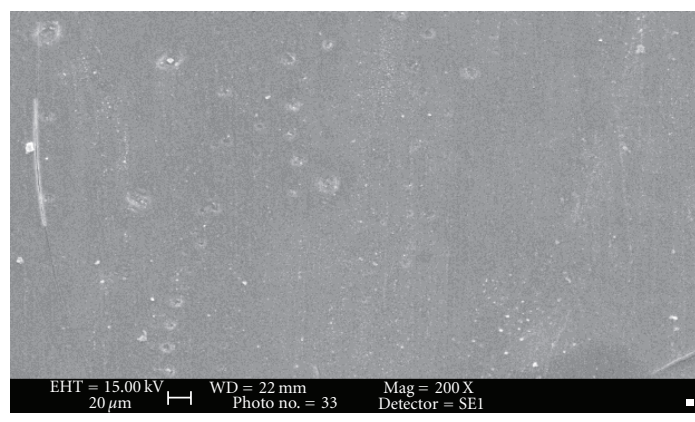

(c)

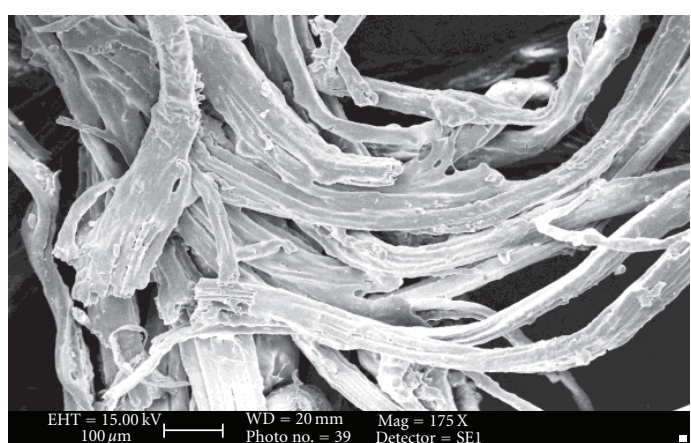

(b)

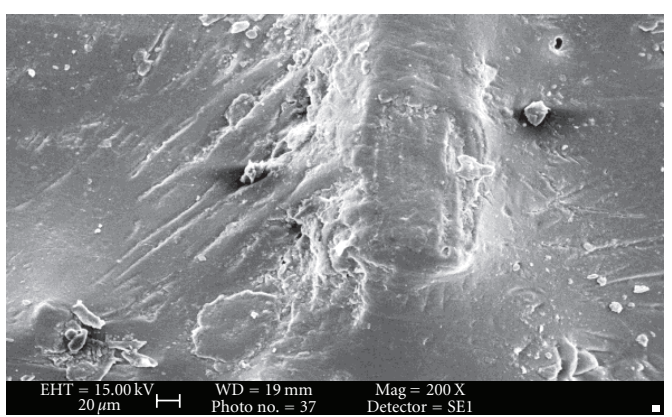

(d)

FIGURE 1: (a) SEM of Hibiscus sabdariffa. (b) SEM of Hs-g-poly(MA-co-EA), Pg: 175. (c) SEM of phenoplast. (d) SEM of Hs-reinforced PF composite.

TABLE 1: Effect of the binary mixtures on Pg using MA as a principal monomer

\begin{tabular}{lcccc}
\hline Sample & $\begin{array}{c}\text { Binary mixture } \\
\left(\times 10^{-3} \text { mole L }^{-1}\right)\end{array}$ & Mean Pg & \pm SD & \pm SE \\
\hline & & & & \\
& $2.21+2.18$ & 110.40 & \pm 5.32 & \pm 3.05 \\
$H$ - -g-poly(MA + VA) & $2.21+2.72$ & 122.00 & \pm 7.10 & \pm 4.10 \\
& $2.21+3.26$ & 136.52 & \pm 5.50 & \pm 3.20 \\
& $2.21+3.72$ & 100.06 & \pm 5.30 & \pm 3.02 \\
& $2.21+4.30$ & 65.04 & \pm 1.75 & \pm 1.04 \\
\hline & $2.21+0.92$ & 98.00 & \pm 4.42 & \pm 2.51 \\
$H s$-g-poly(MA + EA) & $2.21+1.84$ & 136.00 & \pm 2.61 & \pm 1.54 \\
& $2.21+2.76$ & 175.00 & \pm 7.18 & \pm 4.17 \\
& $2.21+3.68$ & 110.00 & \pm 2.57 & \pm 1.49 \\
& $2.21+4.60$ & 75.00 & \pm 2.63 & \pm 1.52 \\
\hline
\end{tabular}

IR spectra of the $H$. sabdariffa and its graft copolymers were recorded with Perkin Elmer Fourier Transform Infrared (FTIR) spectrophotometer using KBr pellets (Sigma Aldrich). Scanning Electron Micrographs (SEMs) of H. sabdariffa and its graft copolymers were obtained by using Electron Microscopy Machine (LEO 435-25-20). Thermogravimetric and differential thermal analyses were performed on thermal analyzer (LINSEIS, L-81 11). Tensile and compressive strength was tested on Universal Testing Machine (HOUNSFIELD, H25KS).

\subsection{Methods}

2.2.1. Graft Copolymerization. Graft copolymerization of the monomer onto $H$. sabdariffa was carried out for optimization of different reaction conditions like reaction time, reaction temperature, monomer concentration, concentration of initiator system, and $\mathrm{pH}$ in order to obtain maximum graft yield. The fiber $(0.5 \mathrm{~g})$ was activated by swelling in $100 \mathrm{~mL}$ of the distilled water for $24 \mathrm{hrs}$. Mixture of ceric ammonium nitrate (CAN) and concentrated $\mathrm{HNO}_{3}$ was slowly added to the reaction medium with continuous stirring followed by the drop-by-drop addition of a definite ratio of binary vinyl monomeric mixture. The reaction was carried out at a definite temperature for a particular time interval. On completion of the reaction, poly(MA), poly(MA-co-VA) and poly(MA-co-EA) were removed on extraction with acetone, methanol, chloroform, and water. The graft copolymer was dried at $50^{\circ} \mathrm{C}$, till a constant weight was obtained. The percent grafting $\left(P_{g}\right)$ was calculated as per the method reported by [1]

$$
P_{g}=\frac{W_{f}-W_{i}}{W_{i}} \times 100,
$$

where $W_{f}$ is the final weight of the fiber and $W_{i}$ is the initial weight of the fiber.

2.2.2. Synthesis of Phenol-Formaldehyde Resin. Phenol-formaldehyde resin was prepared in a resin kettle by taking specific molar ratio of phenol and formalin. Phenol and 
TABLE 2: Thermogravimetric-differential thermal analysis of fiber and composite.

\begin{tabular}{|c|c|c|c|c|}
\hline \multirow{2}{*}{ Sample } & \multicolumn{3}{|c|}{ TGA } & \multirow{2}{*}{$\begin{array}{c}\text { DTA } \\
\text { Peaks in }{ }^{\circ} \mathrm{C}(\mu \mathrm{V})\end{array}$} \\
\hline & IDT & FDT & $\%$ Residue left & \\
\hline \multirow{2}{*}{$\begin{array}{l}\text { H. sabdariffa } \\
\text { Hs-g-poly (MA-co-VA) }\end{array}$} & 225.7 & 463.0 & 20.00 & $139.7(6), 327.9(18.0), 422.7(14)$ \\
\hline & 289.4 & 540.0 & 16.66 & $146.9(8), 347.2(22), 393.9(28.5)$ \\
\hline Phenoplast & 500.0 & 600.0 & - & $551.0(150)$ \\
\hline$H s$-r-PF composite & 540.0 & 680.0 & 10.00 & $610.0(164)$ \\
\hline
\end{tabular}

IDT: initial decomposition temperature; FDT: final decomposition temperature.

TABLE 3: Chemical resistance and moisture absorbance studies of fiber and composite.

\begin{tabular}{|c|c|c|c|c|c|c|c|}
\hline \multirow[t]{2}{*}{ Sample } & \multirow[t]{2}{*}{$\mathrm{Pg}$} & \multicolumn{2}{|c|}{$\begin{array}{l}\text { \% Chemical resistance } \\
\% \text { wt. loss after } 72 \text { hours }\end{array}$} & \multicolumn{4}{|c|}{$\begin{array}{l}\text { \% Moisture absorbance at different RH after } \\
12 \text { hours }\end{array}$} \\
\hline & & $1 \mathrm{~N} \mathrm{HCl}$ & $1 \mathrm{~N} \mathrm{NaOH}$ & $0-35 \%$ & $50-55 \%$ & $60-65 \%$ & $85-90 \%$ \\
\hline H. sabdariffa & - & 55.0 & 43.0 & 0.5 & 0.8 & 1.8 & 2.5 \\
\hline (MA-co-VA) & 136.52 & - & - & - & - & - & 0.2 \\
\hline (MA-co-EA) & 175.00 & - & - & - & - & - & - \\
\hline Phenoplast & - & 04.0 & 02.0 & - & - & 0.3 & 0.5 \\
\hline$H s$-r-PF-composite & - & 01.0 & 一 & - & - & 一 & 0.3 \\
\hline
\end{tabular}

TABLE 4: MOR, MOE, SP, and hardness studies of graft copolymersreinforced PF composite vis-à-vis PF resin.

\begin{tabular}{lcccc}
\hline Composite & \multicolumn{4}{c}{ Strength Test } \\
& $\begin{array}{c}\text { MOR } \\
\left(\mathrm{N} / \mathrm{mm}^{2}\right)\end{array}$ & $\begin{array}{c}\text { MOE } \\
\left(\mathrm{N} / \mathrm{mm}^{2}\right)\end{array}$ & $\begin{array}{c}\text { SP } \\
\left(\mathrm{N} / \mathrm{mm}^{2}\right)\end{array}$ & $\begin{array}{c}\text { Hardness } \\
(\mathrm{HRB})\end{array}$ \\
\hline $\begin{array}{l}\text { Phenol-formaldehyde } \\
43.20\end{array}$ & 496.12 & 38.40 & Brittle \\
H. sabdariffa-r-PF & 69.99 & 614.40 & 57.60 & 67.00 \\
$\begin{array}{l}\text { Hs-g-poly(MA)-r-PF } \\
\text { Hs-g-poly(MA-co- }\end{array}$ & 74.00 & 753.06 & 62.36 & 70.00 \\
$\begin{array}{l}\text { VA)-r-PF } \\
\text { Hs-g-poly(MA-co- }\end{array}$ & 73.20 & 692.92 & 68.00 & 70.00 \\
EA)-r-PF & 74.40 & 700.80 & 69.56 & 75.00 \\
\hline
\end{tabular}

-r-PF refers to reinforced phenol-formaldehyde.

formalin were mixed with the help of mechanical stirrer. Sodium hydroxide solution $(50 \%$ aqueous solution of sodium hydroxide prepared on the basis of $5 \%$ relative weight of sodium hydroxide to the weight of phenol taken) was added to the reaction mixture with constant stirring and heating. Since the reaction was exothermic, the reaction temperature was maintained between $50^{\circ}$ and $60^{\circ} \mathrm{C}$ by circulating the cold water around the resin kettle initially for two hours. Thereafter, reaction temperature was raised to $80-90^{\circ} \mathrm{C}$, and setting of resinification was checked on appearance of turbidity by adding a drop of condensing resin to the cold water. Condensing resin was further heated at this temperature for another two and half hours, and afterwards the resin was cooled to room temperature [9].

2.2.3. Preparation of the Biocomposites. Phenol-formaldehyde matrix-based bio-composites were prepared by mixing fiber and resin $(12.7: 87.3)$. The mixture was then placed in the mold of a particular dimension: $40-80 \mathrm{~mm}$ length,
$5 \times 5 \mathrm{~mm}$ cross-section. Degasification of sample was carried out in compression molding machine, and the samples were kept for curing at $120^{\circ} \mathrm{C}$ for 10 minutes under $400 \mathrm{~kg} / \mathrm{cm}^{2}$ pressure. Composites thus were prepared by reinforcing the raw fiber and its graft copolymers. In each case, the number of specimens used for the determination of mechanical properties was three. Tests were conducted under ambient laboratory conditions [9].

2.2.4. XRD Studies. X-ray diffraction studies were performed on X-ray diffractometer (Bruker D8 Advance) under ambient conditions using $\mathrm{Cu} \mathrm{K} \alpha\left(1.5418^{\circ} \mathrm{A}\right)$ radiation, Ni-filter and scintillation counter as detector at $40 \mathrm{KV}$ and $40 \mathrm{~mA}$ on rotation between $13^{\circ}$ and $25^{\circ}$ at $2 \theta$ scale at 1 sec. step size and increment of 0.01 degree with $0.5^{\circ}$ or $1.0 \mathrm{~mm}$ of divergent and antiscattering slit. The continuous scans were taken and different $d$-spacings ( $\AA$ ) and relative intensities (I) were obtained.

2.2.5. TG-DTA Studies. $6.0 \mathrm{mg}$ of each sample was taken into silica crucible for TG-DTA analysis in air with temperature range varying from $50^{\circ}$ to $600^{\circ} \mathrm{C}$. The heating rate of the sample was $10^{\circ} \mathrm{C}$ per min, and it was scanned for 60 minutes. Results were reported as Delta-M (mg) versus temperature $\left({ }^{\circ} \mathrm{C}\right)$ in case of TGA while DTA signal $(\mu \mathrm{V})$ versus temperature $\left({ }^{\circ} \mathrm{C}\right)$ in case of DTA studies.

\subsection{Physicochemical Evaluation}

2.3.1. Moisture Absorption Study. Moisture absorbance studies at various relative humidity levels were carried out as per the method reported earlier. Moisture absorbance percentage was found out by placing a known weight (Wi) of dry grafted, 


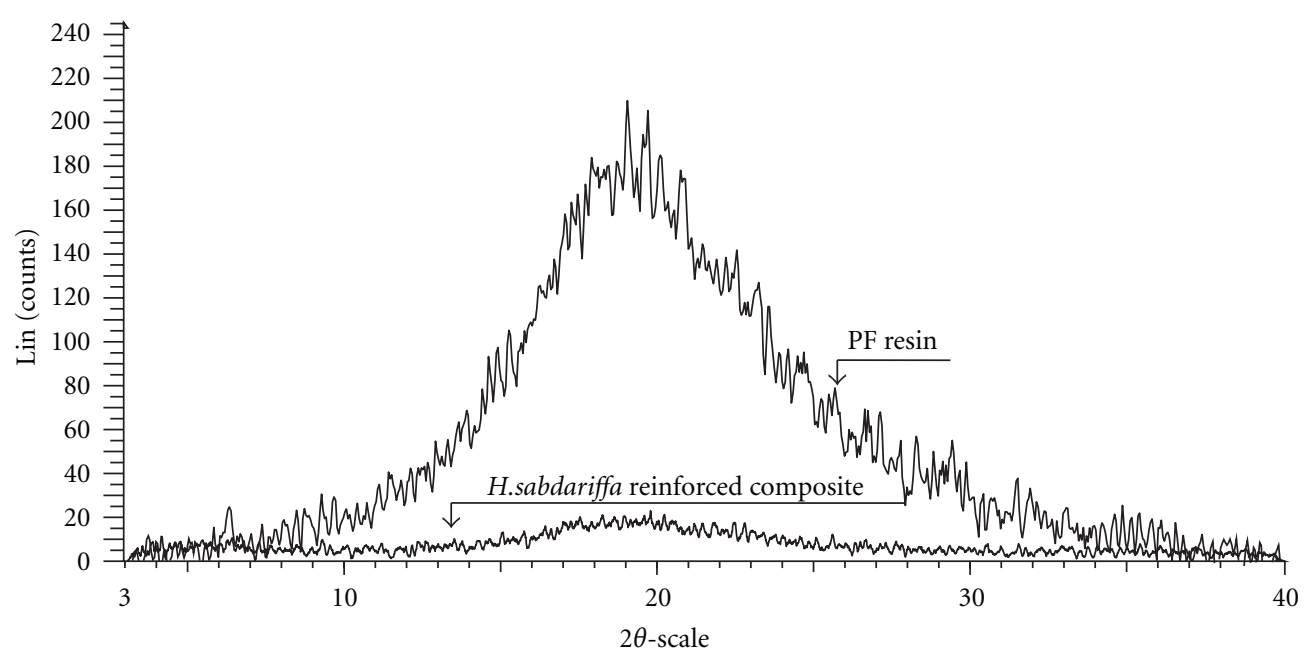

FIGURE 2: The XRD overlay of PF resin and H. sabdariffa-reinforced composite.

ungrafted, and composite samples in a humidity chamber for about twelve hours and then the final weight $\left(W_{f}\right)$ of the samples exposed to different relative humidities ranging from 30 to $90 \%$ was taken. The \% moisture absorbance was calculated from the increase in initial weight in the following manner [10]:

$$
\text { Moisture absorbance }(\%)=\left[\frac{\left(W_{f}-W_{i}\right)}{W_{i}}\right] \times 100 \text {. }
$$

2.3.2. Acid and Base Resistance. Acid and base resistance studies were carried out as per the method reported in (3). Acid and base resistance was studied by placing a known weight (Wi) of dry grafted, ungrafted samples, and composite in fixed volume $(50 \mathrm{~mL})$ of $1 \mathrm{~N} \mathrm{HCl}$ and $1 \mathrm{~N}$ $\mathrm{NaOH}$, and the final weights $\left(W_{f}\right)$ of the samples were noted after 72 hours [10]:

$$
\text { Weight loss }(\%)=\left[\frac{\left(W_{i}-W_{f}\right)}{W_{i}}\right] \times 100 .
$$

\subsection{Mechanical Evaluation}

2.4.1. Modulus of Rupture. MOR was determined according to ASTM D 790 standard and was calculated using [9]

$$
\mathrm{MOR}=\frac{3 P L}{2 b d^{2}} \mathrm{~N} / \mathrm{mm}^{2}
$$

where $P$ is the peak load, $L$ the length of the sample, $b$ the width of the sample, and $d$ the thickness of the sample.

2.4.2. Modulus of Elasticity. MOE was determined according to ASTM D 790 standard and was calculated using the following equation [9]

$$
\mathrm{MOE}=\frac{P_{1} L^{3}}{4 b d^{3} y} \frac{\mathrm{N}}{\mathrm{mm}^{2}},
$$

where $P$ is the peak load, $L$ the length of the sample, $b$ the width of the sample, $d$ the thickness of the sample, $P_{1}$ the load at the limit of proportionality, and $y=$ rate of bending.

2.4.3. Stress at the Limit of Proportionality. Stress at the limit of proportionality was calculated by using [9]

$$
\mathrm{SP}=\frac{3 P_{1} L}{2 b d^{2}} \frac{\mathrm{N}}{\mathrm{mm}^{2}},
$$

where $P_{1}$ is the load at the limit of proportionality, $L$ the length of the sample, $b$ the width of the sample, and $d$ the thickness of the sample.

2.4.4. Hardness. Hardness of the composites was tested using Rockwell Hardness tester (Balancing Instrument and Equipments Miraj Pvt. Ltd., Model-TSM) following ASTM D785 standard, using B-scale $100 \mathrm{Kg}$ as a major load and $10 \mathrm{Kg}$ as a minor load with 1/16 inch indenter steel ball, and it was measured in HRB.

\section{Results and Discussion}

Ceric ammonium nitrate used as source of ceric ion in presence of concentrated nitric acid plays an important role during graft copolymerization. Because of the large-size [Ce$\mathrm{O}-\mathrm{Ce}]^{6+}$ ion it is unable to form complex with the fiber, whereas in presence of $\mathrm{HNO}_{3}$ more and more of $\mathrm{Ce}^{4+}$ and $\left[\mathrm{Ce}(\mathrm{OH})_{3}\right]^{3+}$ ions are formed and these ions easily undergo complex formation with the hydroxyl groups of fiber. Ceric ion forms the chelate complex with the cellulose molecule through C-2 and C-3 hydroxyl groups of the anhydroglucose unit. Transfer of the electron from the cellulose molecule to $\mathrm{Ce}$ (IV) would follow, leading to its reduction to $\mathrm{Ce}$ (III), breakage of the bonds at C-2 and C-3, resulting in the formation of the free radical sites. Graft yield and homopolymer formation have been found to be the functions of both the monomer and initiator concentrations (Figure 3) $[10,11]$. 


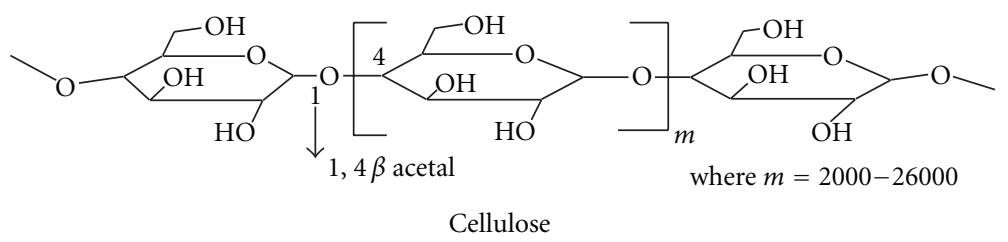

FIgUre 3: Cellulose.

3.1. Optimization of Different Reaction Parameters and Effect of Binary Vinyl Monomeric Mixture. The optimized parameters for the graft copolymerization of MA (as a principal monomer) onto $H$. sabdariffa fiber to obtain the maximum graft yield $(60.24 \%: \mathrm{SD} \pm 3.57, \mathrm{SE} \pm 2.06)$ were: temperature $\left({ }^{\circ} \mathrm{C}\right), 35$; time (minute): 120; CAN $\left(\mathrm{mol} \mathrm{L}^{-1}\right): 1.49 \times 10^{-4}$; $\mathrm{HNO}_{3}(\mathrm{~mol} \mathrm{~L}-1): 3.36 \times 10^{-3}$; $\mathrm{MA}\left(\mathrm{mol} \mathrm{L}{ }^{-1}\right): 2.21 \times$ $10^{-3}$, and $\mathrm{pH}$ 7.0. From the literature review it is clear that the reactivity of the acrylate monomers in reference to styrene radicals is normally higher. Since the carboalkoxy group is highly electronegative, it causes the acrylate double bond to be positive in character. Methyl acrylate radical has hyperconjugative resonance with methyl hydrogen as well as with the carboxy group. The polar character of the acrylates results in the penultimate group effects in both propagation and the termination reactions. Vinyl acrylate and ethyl acrylate both have effective monomeric properties $\left(K_{p}, K_{t}, K_{p} / K_{t}\right.$, and $\left.C_{m}\right)$, and their efficient reactivity ratio and interaction with the primary monomers result in high $P g$ (Table 1). However, many other factors also determine the graft yield like the type of fiber, swelling, number of active sites, the nature and amount of the solvent and temperature of polymerization strongly influencing the reactivity ratios. In absence of monomer rich phase, the diluents will compete with the monomers for adsorption sites. The amount of adsorption will depend upon the total amount of surface area present, and this, in turn, is dependent upon the rate of stirring. Physical factors like mixing efficiency determine the melt temperature, the pressure, the rheological properties, solubility of the initiator and the monomer. Elevated temperature favors the degradation, reduces the initiator half-life, modifies the rate or specificity of the reaction, and influences the solubility and rheological parameters [12, 13].

\section{Characterization}

4.1. FTIR and SEM. IR spectrum of the H. sabdariffa showed a broad peak at $3424.0 \mathrm{~cm}^{-1}$ (-OH group), and peaks at $2924.7 \mathrm{~cm}^{-1}, 1246.9 \mathrm{~cm}^{-1}$, and $1032.0 \mathrm{~cm}^{-1}$ were observed due to $-\mathrm{CH}_{2}, \mathrm{C}-\mathrm{C}$, and $\mathrm{C}-\mathrm{O}$ stretching, respectively. However, the additional peak was observed due to $\mathrm{MA}(>\mathrm{C}=\mathrm{O}$ peak) at $1738 \mathrm{~cm}^{-1}$. In all the cases the incorporated groups of secondary monomers were seen at $1638.0 \mathrm{~cm}^{-1}$ (vinyl group) in $H s$-g-poly(MA-co-VA) and $1735.0 \mathrm{~cm}^{-1}(>\mathrm{C}=\mathrm{O}$ group) in $\mathrm{Hs}$-g-poly(MA-co-EA), respectively.

In SEM, the cellulose was gold plated to have an impact. It is quite evident from Figures 1(a) and 1(b) that there has been a sufficient deposition of polyvinyl monomers onto fiber. Comparison of the scanning electron micrographs of the phenoplast with $H$. sabdariffa-reinforced PF composite reveals the distinction between the surfaces due to incorporation of the reinforced fiber (Figures $1(\mathrm{c})$ and $1(\mathrm{~d})$ ).

4.2. XRD Studies. The XRD overlay of the PF resin and the $H s$-reinforced PF resin is given in Figure 2, which shows a distinct change in crystallinity after fiber reinforcement.

4.3. Thermal Evaluation. Thermogravimetric and differential thermal analysis studies were carried out at the heating rate of $10^{\circ} \mathrm{C} /$ second. The TGA results of the $\mathrm{PF}$ composite (Table 2) showed $500^{\circ} \mathrm{C}$ and $600^{\circ} \mathrm{C}$ as the initial decomposition temperature and final decomposition temperature, respectively. The percentage weight loss during this decomposition was found to be $26.61 \%$ in the temperature range of $50-500^{\circ} \mathrm{C}$ while it was $73.39 \%$ during the final decomposition in the temperature range of $500-600^{\circ} \mathrm{C}$. The higher initial and final decomposition temperature could be due to three-dimensional network structure of the thermoset. The DTA showed prominent exothermic peaks at $551^{\circ} \mathrm{C}(150 \mu \mathrm{V})$ that correspond to the major decomposition due to irreversible decomposition of the crystallites between 500 and $600^{\circ} \mathrm{C}$ as a function of temperature, respectively. The IDT, FDT of fiber-reinforced composites have increased due to strong fiber matrix interaction. The grafted monomer acts as coupling agent and elevates the decomposition temperature. Cellulose in $H$. sabdariffa degrades by dehydration, glycogen formation, and depolymerization. In case of $H$. sabdariffa, two-stage decomposition has been found: the former stage is attributed to loss by dehydration, volatilization processes, whereas the later stage is attributed to loss by depolymerization, delignification, and oxidation of the char $[10,14]$. The addition of graft copolymer as reinforcement further increased the thermal stability of the composites.

\section{Physicochemical Evaluation}

5.1. Moisture Absorption Study. It was found that graft copolymerization of vinyl monomer onto $H$. sabdariffa has a great impact on the moisture absorbance behavior (Table 3 ). It has been observed that, with increase in graft yield, there was a decrease in percent moisture absorbance. This was due to blocking of sites vulnerable for moisture absorbance with vinyl monomer chains, thereby converting the fiber to be less sensitive to moisture $[6,10]$. The incorporation of graft copolymers in the phenoplast improved the fiber matrix interaction that decreased the pores and increased the strength by acting as coupling agent. 
5.2. Acid and Base Resistance. It has been observed that acid base resistance of the fiber increased with increase in percent grafting. This is due to the fact that poly(vinyl) chains grafted onto $H$. sabdariffa fiber have less affinity for $1 \mathrm{~N} \mathrm{HCl}$ and $1 \mathrm{~N} \mathrm{NaOH}$ as compared to free hydroxyl groups present in ungrafted fiber. Therefore, the resistance of fiber towards acid base was found to increase with the incorporation of poly(vinyl) chains on the active sites of the backbone (Table 3) [6]. The incorporation of graft copolymers in the phenoplast improved the fiber matrix interaction that increased the strength of the composite.

\section{Mechanical Evaluation}

6.1. MOR, MOE, SP, and Hardness. The results obtained after the mechanical evaluation of phenoplast, fiberreinforced composites, and grafted-fiber-reinforced biocomposites are given in Table 4 . The results clearly show that grafted fiber has enhanced the mechanical strength of the composites.

Thus, it is evident from the results that $H$. sabdariffa fiber as reinforcement has improved the mechanical properties of the P-F composites. In most of the cases, graft copolymers of methyl acrylate and its binary mixtures were found to exhibit better mechanical behavior such as wear resistance, tensile strength, compressive strength, MOR, MOE, SP and hardness as compared to the raw fiber-reinforced P-F composites and the phenoplast. The better mechanical behavior could be accounted for by the functioning of the monomer as a coupling agent, better polymer matrix interaction, compatibility and orientation of the fiber. However, some deviation in the results could be justified by other governing factors for overall mechanical performance like nature and amount of matrix and fiber, orientation, distribution of the fiber with respect to the matrix axis, form of reinforcement used (woven or nonwoven, grafted or ungrafted), strength of the interfacial bond between the fiber and matrix, length of the fiber (continuous or discontinuous), and aspect ratio that on mere imbalance may lead to debonding and cracking $[1,15,16]$.

\section{Conclusion}

H. sabdariffa stem fiber when grafted with methyl acrylate and its binary vinyl monomeric mixture in the presence of ceric ion initiator yielded novel regenerated graft copolymers. It is evident from the characterization and evaluation studies of the graft copolymers through different techniques that grafting resulted in the morphological transformation that improved the various physico-chemicothermal properties of the H. sabdariffa fiber. The use of Hibiscus sabdariffa and its graft copolymers as reinforcement in polymer matrix-based composites has improved the mechanical strength of these bio-composites. The use of renewable waste biomass as graft copolymers and as reinforcement to form bio-composites can have numerous scientific and industrial applications. These advanced materials can be used in transportation, packaging, aerospace, and insulators to serve as innovation and pioneering for the advancement of science and technology.

\section{References}

[1] A. Chauhan, Synthesis and evaluation of physico-chemicomechanical properties of polymer matrix based composites using graft copolymers of Hibiscus sabdariffa as reinforcing agents, Ph.D. thesis, Punjab Technical University, 2009, chapter 5.

[2] B. S. Kaith, A. S. Singha, and K. S. Sharma, "Synthesis of graft copolymers of binary vinyl monomer mixtures and flax fiber using FAS-KPS redox system," International Journal of Chemical Science, vol. 2, pp. 37-43, 2004.

[3] B. S. Kaith, A. S. Singha, and K. S. Sharma, "Graft copolymerization of flax fiberswith binary vinyl monomer mixtures and evaluation of swelling, moisture absorbance and thermal behavior of the grafted fibers," Journal of Polymeric Materials, vol. 20, p. 195, 2003.

[4] B. S. Kaith, A. S. Singha, D. K. Dwivedi, S. Kumar, D. Kumar, and D. Dhemeniya, "Preparation of polystyrene matrix based composites using flax-g-copolymers as reinforcing agent and evaluation of the mechanical behavior," International Journal of Plastic Technology, vol. 7, pp. 119-125, 2003.

[5] B. S. Kaith and S. Kalia, "Synthesis and characterization of graft co-polymers of flax fiber with binary vinyl monomers," International Journal of Polymer Analysis and Characterization, vol. 12, no. 5, pp. 401-412, 2007.

[6] A. S. Singha, B. S. Kaith, and S. Kumar, "Evaluation of physical and chemical properties of FAS-KPS induced graft Co-polymerization of binary vinyl monomer mixtures ontomercerized flax," International Journal of Chemical Sciences, vol. 2, no. 3, p. 472, 2004.

[7] M. S. Thacker, Raw Materials, The Wealth of India, Malvaceae Vol. V, H-K, 80, CSIR Publisher, New Delhi, India, 1997.

[8] J. Junkasem, J. Menges, and P. Supaphol, "Mechanical properties of injection-molded isotactic polypropylene/roselle fiber composites," Journal of Applied Polymer Science, vol. 101, no. 5, pp. 3291-3300, 2006.

[9] B. S. Kaith and A. Chauhan, "Synthesis, characterization and mechanical evaluation of the phenol-formaldehyde composites," E-Journal of Chemistry, vol. 5, supplement 1, pp. 10151020, 2008.

[10] A. Chauhan and B. Kaith, "Synthesis, characterization and chemical studies of Hibiscus sabdariffa-g-copolymers," Fibers and Polymers, vol. 12, no. 1, pp. 1-7, 2011.

[11] G. Mino and S. Kaizerman, "A new method for the preparation of graft copolymers. Polymerization initiated by ceric ion redox systems," Journal of Polymer Science, vol. 31, no. 122, pp. 242-243, 1958.

[12] J. Brandrup and E. H. Immergut, Polymer Handbook, vol. 2, Wiley Interscience; John Wiley \& Sons, New York, NY, USA, 1975.

[13] G. Ham, High Polymer, Copolymerization, vol. 18, Interscience Publishers, New York, NY, USA, 1964.

[14] S. Ouajai and R. A. Shanks, "Composition, structure and thermal degradation of hemp cellulose after chemical treatments," Polymer Degradation and Stability, vol. 89, no. 2, pp. 327-335, 2005. 
[15] I. Ahmad, T. S. Chin, C. K. Cheong, A. Jalar, and I. Abdullah, "Study of fiber surface treatment on reinforcement/matrix interaction in Twaron fiber/ENR composites," American Journal of Applied Sciences, pp. 14-20, 2005.

[16] S. Chawala, A Text Book of Engineering Chemistry, Polymers, Dhanpat Rai \& Co, New Delhi, India, 2002. 

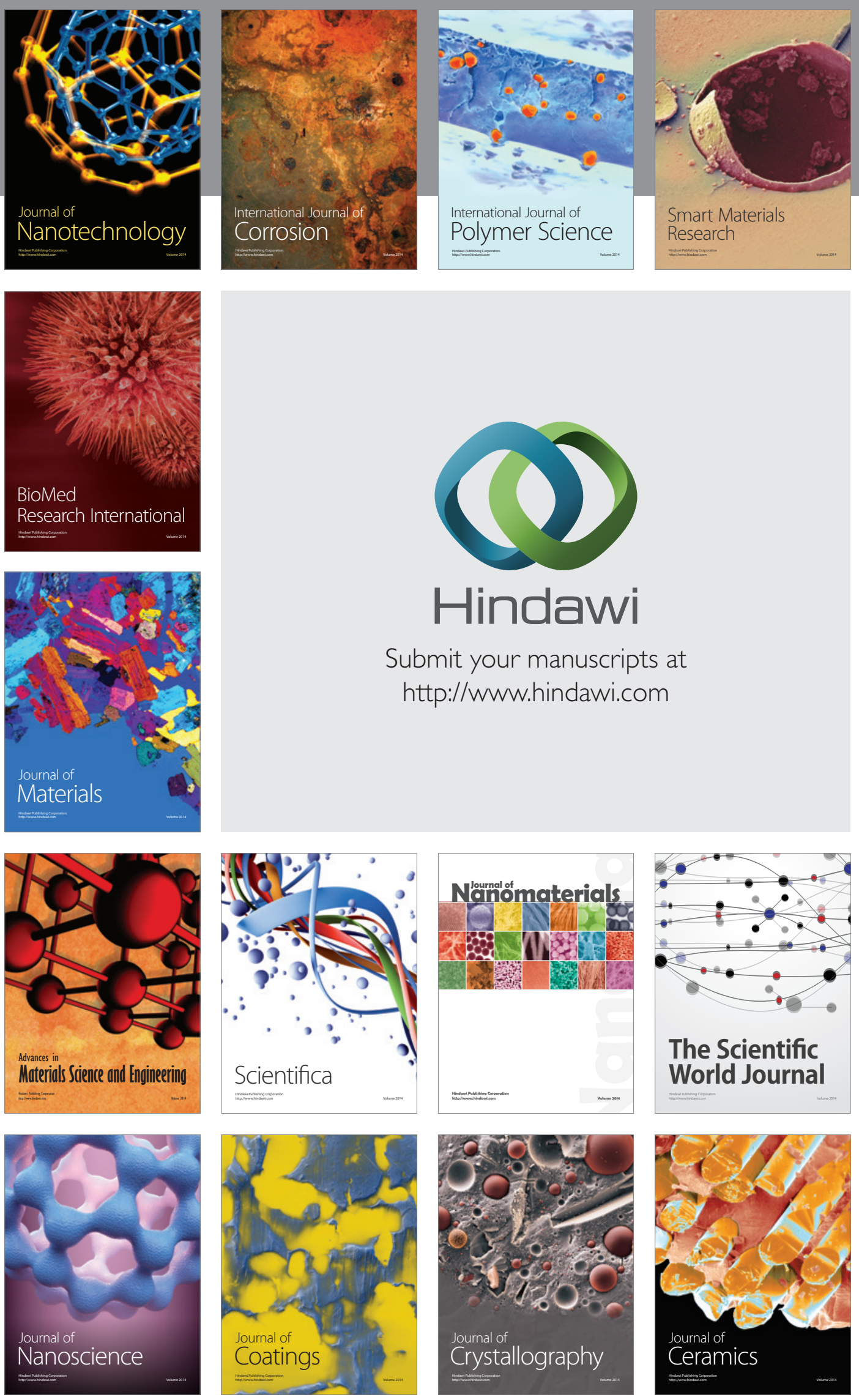

The Scientific World Journal

Submit your manuscripts at

http://www.hindawi.com

\section{World Journal}

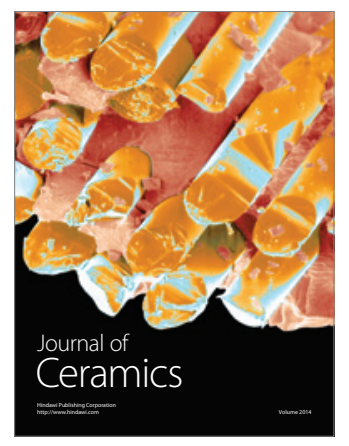

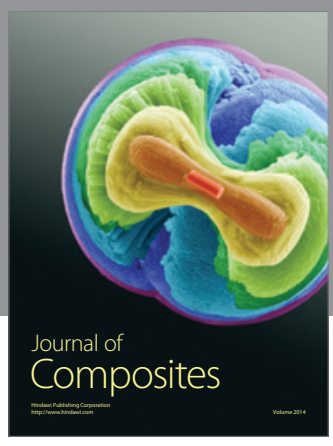
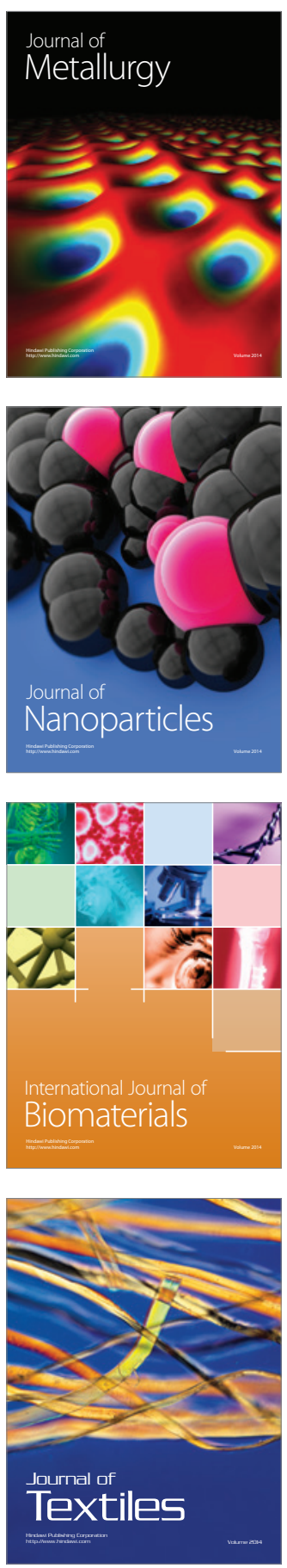